\title{
Connectivism and Connective Learning
}

\author{
Shqipe Husaj, PhD Cand. \\ Lecturer at the University "Haxhi Zeka"-Peje- Kosovo \\ Shqipehusaj5@gmail.com; Shqipe.husaj@unhz.eu
}

Doi:10.5901/ajis.2015.v4n1s2p227

\begin{abstract}
The rapid development in technology has brought the world to a small village enabling people to meet each other any time they want, exchange their knowledge and experiences being seated at home or office by using just a small equipment. Technology generates new affordances with new pedagogical options. In this sense the technology enables us distribute knowledge over network connections in an uncontrolled way, by being active member and committing ourselves to the whole process of communication and learning. The purpose of this paper is to bring some ideas on learning through technology respectively ideas on connectivism or connective learning, the principles of connective learning at numerous levels etc. As its name suggests connectivism is the knowledge distributed across a network of connections, and therefore that learning consists of the ability to put those networks into progressive use. It means the set of connections formed by actions and experiences. Some characteristics of Connective learning, online courses and knowledge sharing through networks will be compared to traditional classroom learning.
\end{abstract}

Keywords: connectivism, connective learning, network connection, traditional classroom, etc.

\section{Introduction}

Education has become one of the fastest growing "businesses" in recent years. There are many new universities and schools opened everyday everywhere in the world, be it in private or public sector accompanied with TV commercials or other advertising campaigns or promotions for their study programs whether online or at campuses. Online education has become more popular in today's fast growing society. Online courses allow students to take courses from different states and even from different countries in different fields. Simply, online learning is electronic learning, and typically this means using a computer to deliver part, or all of a course whether it's in a school, part of your mandatory business training or a full distance learning course. However there is no substitute for traditional learning since students feel more confident in gaining knowledge being instructed by the teacher, in a friendly atmosphere using books, notebooks, blackboard, desks, chalk and other necessary learning tools.

\section{What is Connectivism?}

- Connectivism is a learning theory promoted by Stephen Downes and George Siemens. George Siemens claims in his 2004 article"Connectivism: A Learning Theory for the Digital Age" that the connectivism that he proposes is a learning theory. A learning theory which he characterizes as the "amplification of learning, knowledge and understanding through the extension of a personal network". Called a learning theory for a digital age, it seeks to explain complex learning in a rapidly changing social digital world. The rapid development in technology has brought the world to a small village enabling people to meet each other any time they want, exchange their knowledge and experiences being seated at home or office by using just a small equipment. Thus, the job of an educator has become much easier and more effective. Educators wherever they are should consider the work of thinkers like Siemens and Downes. In the theory, learning occurs through connections within networks. The model uses the concept of a network with nodes and connections to define learning. Learners recognize and interpret patterns and are influenced by the diversity of networks, strength of ties and their context. The knowledge is transferred by connecting to and growing personal networks, sharing with the group everything we know, everything we believe in or imagine expressed in sentences and concepts. This way of transferring and exchanging knowledge pedagogically is much more useful because it should be treated more as communication. By continuously communicating with a large 
number of people in a network new information is acquired and further processed. In connectivist learning students discuss and learn course contents, give ideas and see that it is a fluid, variable, contextual and critical for the learners. Decision-making is itself a learning process. Choosing what to learn and the meaning of incoming information is seen through the lens of shifting reality. While there is a right answer now, it may be wrong tomorrow due to alterations in the information climate impacting the decision. Learning is a knowledge creation process....not only knowledge consumption. Learning tools and design methodologies should seek to capitalize on this trait of learning. A Connectivist course therefore has two major modes: 1 . a creation of an environment (and expectation) of great diversity, creating multiple points of view on an amorphous body of material, domain or discipline and 2. creation of new and unexpected knowledge as a result of the interaction of participants from those different points of view. Learning happens in many different ways. Courses, email, communities, conversations, web search, email lists, reading blogs, etc. Courses are not the primary conduit for learning. Different approaches and personal skills are needed to learn effectively in today's society. For example, the ability to see connections between fields, ideas, and concepts is a core skill.

In connectivism a generation that learns, works, entertains and expresses itself through open collaborative tools like You Tube, Google Talk, Flicker, eMute and Del.ico ( Downes, 20050). It means, the social context provided by connectivism is a new way of learning developed under a collaboration framework;

- Collection; store data, organize resources, filter information and create new contacts.

- Reflection; think critically, choose and review information, set up new learning itineraries.

- Connection; spontaneously form working groups, integrate oneself into existing learning communities, share learning objectives, values and attitudes, link information.

- Publication; share learning experiences, edit content in a large variety of formats, convert collaborative tools into cognitive tools

Principles of Connectivism

According to George Siemens, "Connectivism is the integration of principles explored by chaos, network, and complexity and self-organization theories. Learning is a process that occurs within nebulous environments of shifting core elements - not entirely under the control of the individual. Learning (defined as actionable knowledge) can reside outside of ourselves (within an organization or a database), is focused on connecting specialized information sets, and the connections that enable us to learn more are more important than our current state of knowing.

Siemen's Principles of connectivism are as follows:

- Learning and knowledge rests in diversity of opinions.

- Learning is a process of connecting specialized nodes or information sources.

- Learning may reside in non-human appliances.

- Capacity to know more is more critical than what is currently known

- Nurturing and maintaining connections is needed to facilitate continual learning.

- Ability to see connections between fields, ideas, and concepts is a core skill.

- Currency (accurate, up-to-date knowledge) is the intent of all connectivist learning activities.

- Decision-making is itself a learning process. Choosing what to learn and the meaning of incoming information is seen through the lens of a shifting reality. While there is a right answer now, it may be wrong tomorrow due to alterations in the information climate affecting the decision.

\section{Traditional Learning Vs. Connectivism}

There is always the other way of doing something, by comparing advantages and disadvantages of both ways. Even though the technology has brought things closer and easier for everyone, the traditional way of doing and getting things still remains preferable for many people. Besides classroom and blackboard there are more differences between connectivist learning and traditional learning. Students participating in connectivist learning, experience different scores, different methods and a different lifestyle compared to those enrolled in institutions . Learning in a traditional classroom which by some students is considered beneficial because they can interact with the teacher and their classmates. This true especially students who find it better to interact face-to-face and prefer activities and group work. The possibility of asking questions and receiving an immediate response from their teacher is important since it makes student feel more active and develop lifelong contacts, memories and experiences that humanize the educational experience in a way that online learning does not. Some students need to feel sure that what they do is correct and that they are going in the right 
direction, so they need feedback to keep them moving. In addition, traditional classroom learning provides students with a fixed schedule and specific periods dedicated to learning. In traditional schools and classrooms so called "brick and mortar" people are comfortable with classroom structure and sometimes don't want to deviate from it. If you turn in a paper and have a question about grades or comments, you can usually talk to the teacher and analyze body language. In online learning- as we addressed in this paper as connectivism it is sometimes harder to gauge effective communication and you may have to wait until you get an answer or explanation. While many students relish new advances in technology, others aren't as comfortable with technology and prefer paper and pencil based methods. For these students, the familiarity and comfort of traditional schools is an advantage. Traditional classes may be a better fit for students with limited resources and limited computer access. Considering that most adults have jobs to earn for their studies, sometimes it is difficult to find time for personal study between working hours and computer meetings, or have no sufficient knowledge in technology so, students in this situation prefer schedule classes first and other school activities.

Traditional schools have a defined structure and classes meet at the same time each week on certain days while in connectivism there is a certain number of times to post your comments and if you loose your timing then there is no chance to get on the right track. Students who fail to make online connections with other learners in their group feel isolated and more stressed Typically, a student in a connectivist course read some of the writings and comments, listen to or watch some of the recordings, post comments in threaded discussion forums, create a blog and post comments and responses, that for some students is considered a waste of time sitting on the computer and waiting for the others to respond or to get an explanation, while in traditional classes comments and explanations are given immediately . Not everybody feels comfortable learning in a large group, especially if they understand things harder than other co-learners. Connectivism allows each individual to tackle the at their own pace, with interactive tasks being set in place to ensure a thorough understanding through each module. Online learning is ideal for those with unconventional work hours , those working full time, those serving in military or those raising a family and seeking a degree in a certain field. They are cheaper because there are no fees be paid for maintaining a large campus and its classrooms , so it is able to pass saving to students of all ages. In a New York Times article, experts declare that the real promise of online education is "providing learning experiencesthat are more tailored to individual students than is possible in classrooms", which in turn fosters the concept of "learning by doing" Many students find this engagement more useful and more relevant therefore performing better than those receiving traditional instruction. But the personal engagement and motivation should be taken into consideration since, almost half of the participants don't have English as a first language. It means students need much more commitment than those who take lessons in their mother tongue. As Dr. Ralph Kuehn, Director of Mentors and Quality Assurance at Northcentral University ( Kuehn.R, January 30, 2013 ) said: " in seeking an online degree, each student relies upon their own motivation to complete each course and to eventually graduate." Kuehn continues that this motivation is a strong proponent for success. Online education is considered a viable option in education. At one time online education was not considered very professional in the job market. Employers do not prefer hiring employees with online degrees. Traditional education degrees are more accepted and preferable by employers.

\section{Some differences between traditional learning and Online learning:}

\section{Traditional learning:}

- Learning in the classroom with large number of students.

- Black table, chalk, books, notebooks, pen, pencil, desks, chairsnecessary for the process.

- Books edited many years before the year of learning process going on.

- Limited time of visiting school- no changes possible on the timetable.

- Opportunity to join on campus clubs and extracurricular activities
Online learning:

-Learning with smaller virtual group in better infrastructure

- Table and a computer

- Updated Online books and articles

- Learning can take place in the workplace, at home, school or anywhere

-Limited direct contact with colleagues and professors.

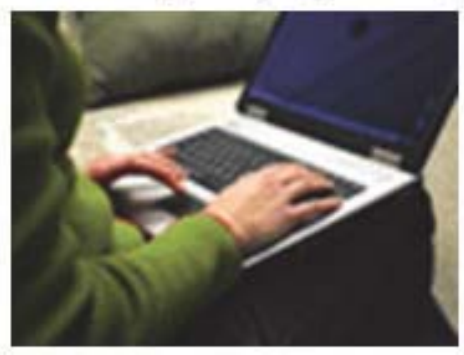


Good courses, whether on campus or online, are engaging and foster active learning communities. In the best online courses, learners connect, collaborate, inspire, discover and create through myriad technologies.

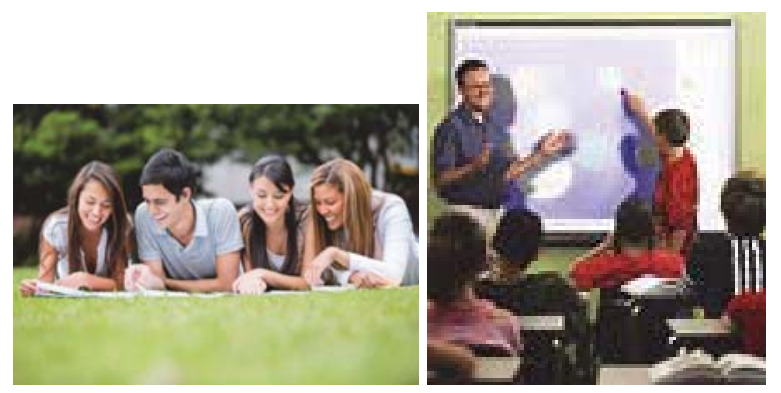

A face-to-face meeting in a classroom imposes accountability, inspires effort and promotes academic responsibility in subtle ways that we don't fully appreciate. On a campus, students attend class and stay alert because they worry what the teacher will think if they don't. Once they're in the classroom, the battle is mostly won.

Your knowledge of the subject is an important factor in whether you choose online education or traditional education. If you're an expert or at least have a working knowledge about the subject, taking an online class in that subject could be beneficial. On the other hand, if you don't know anything about the subject and you have little or no background knowledge, a traditional course might be a better option for you. Many schools offer online and traditional courses that may give you the best of both worlds, or at least the opportunity to experience both.

Student's personality type can also be significant in choosing whether to pursue an online education as opposed to traditional education. Are you an introvert or an extrovert? By nature, an introvert may feel more comfortable in an online education environment because she/he won't have to interact in-person. Student can learn in the comfort at home, independent of others. An extrovert, on the other hand, may prefer a more social education experience and enjoy regular in-person interaction with others.

- By reducing the time taken away from the office, removing travel costs and doing away with printed materials, online learning helps you to save money and increase workplace productivity for those who are employed. It also means your staff will be happier and focused. The cost of online education may cost slightly less than traditional education, but this isn't the case with all programs. Typically, online schools don't have to deal with the costs of classrooms or the upkeep of classrooms the way traditional education does, cutting operation. Housing costs for students is another expense that online education students don't have to contend with. Additionally, online programs usually cut the transportation costs of traveling to and from school that those in online programs do not face.

\section{Conclusion}

Traditional schools offer students ways to interact with teachers and peers in a way that online formats do not. While many online courses integrate some form of physical interaction in hybrid courses, courses that are entirely online do not have a face to face component. While you may see your professor on video, you can't raise your hand and get immediate feedback or lean over to your classmate and ask a question. Also, the level of interaction with your peers isn't the same in online learning as it is in traditional classroom atmospheres. Many face to face courses only operate within normal office hours. By allowing staff to complete the course when and where they like you can make sure disruptions to your busy working schedule are minimized.. As student is the one to decide which learning environment is right for him/her, they should not forget that the biggest difference is the impact of that education and that degree will have in your life. Online and traditional both seek profitability in life.

\section{References}

George Siemens maintains a blog and a wiki at http://www.connectivism.ca/wiki/FrontPage

Connectivism: a theory for learning in a world of growing complexity. By Kay Strong, Holly Hutchins. impact: Journal of Applied Research in Workplace E-learning, Vol 1, No 1 (2009)

Connectivism glossary, http://en.wikiversity.org/wiki/Connectivism_glossary update

http://www.irrodl.org/index.php/irrodl/article/view/902/1664 